\title{
TENSION CRACKS PARALLEL WITH THE AXIAL PLANE
}

\author{
Nils Edelman
}

\begin{abstract}
Edelman, Nils 1973: Tension cracks parallel with the axial plane. Bull. Geol. Soc. Finland 45, 61-65.

Tension cracks parallel with the axial plane are rather common in the archipelago of southwestern Finland. They are filled with pegmatite or quartz. They are here attributed to secondary elastic stresses in the axial plane.
\end{abstract}

Nils Edelman, Geologisk-mineralogiska institutionen, Abo Akademi, SF-20500 Abo 50, Finland.

\section{Introduction}

During field work in the archipelago of southwestern Finland, many tension cracks parallel with the axial plane were observed. As the axial plane is nearly perpendicular to the folding stress, it seemed odd that tension cracks had formed in this direction. These cracks are too common to be due to pure coincidence, so I shall here discuss a possible causal connection between the tension cracks and the folding.

\section{Description}

The tension cracks are parallel or subparallel with the axial plane in the folds. They show very different styles in different rocks. The cracks vary in length from a few centimetres to several metres and in shape from small elliptical ones, with a length-breadth ratio of about 2 , through lenticular ones, with ratios of about 20 , to thin, nearly uniformly broad ones. They are filled with pegmatite or, in some instances, quartz.
At the southern point of the islet of Haraholm, east of Nagu Sandö, there occurs a fine-grained gneiss with graded bedding, which contains small, irregularly elliptical pegmatite clots elongated in the direction of the axial plane (Fig. 1). Whether they are lenticular or elongated in the direction of the fold axis is impossible to decide on the flat surface. The lenses consist of feldspar and quartz.

Farther northwest on the shore of Haraholm, an occurrence of varved gneiss contains pegmatite lenses with a much greater lengthbreadth ratio (Fig. 2). They lie in the axial plane, which here obliquely cuts through the bedding. Some of them lie en echelon in the dark parts of the varves, but others are located partly or entirely in the light parts. Especially the pegmatite lenses in the light parts are surrounded by dark rims. This is most easily explained by a migration of the salic components from the borders into the pegmatite. Similar dark-rimmed pegmatites have been described earlier (Edelman 1956, 1960; Reitan 1959). 


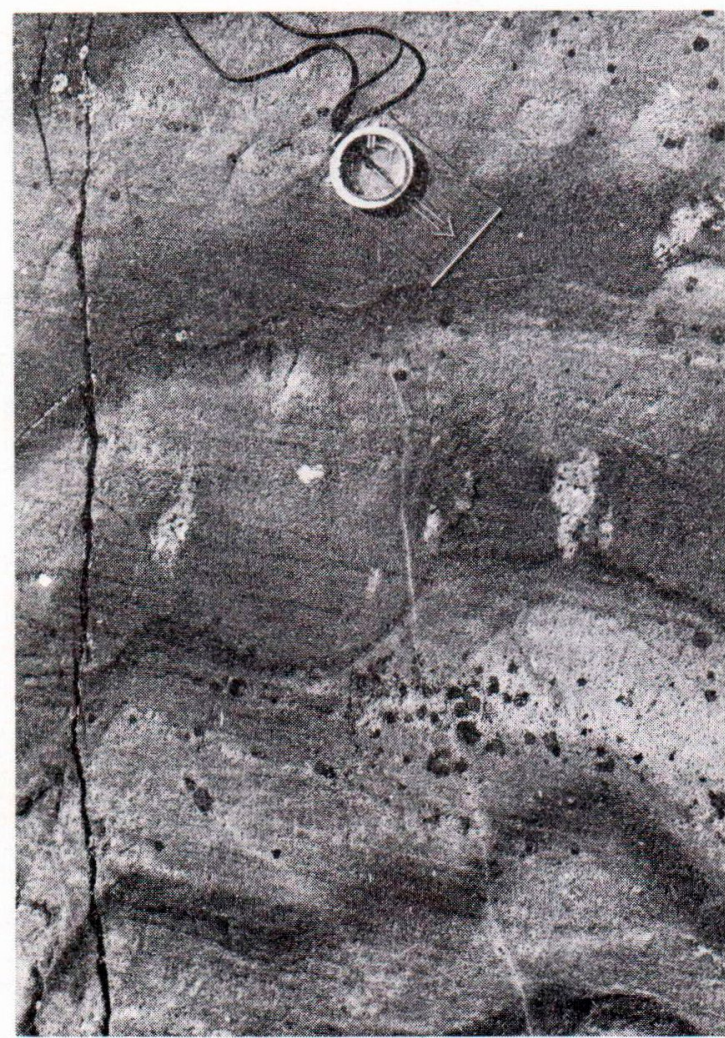

Fig. 1. Gneiss with graded bedding. Irregular pegmatite lenses elongated in the direction of the axial plane occur in the dark parts of the varves. Southern point of the islet of Haraholm, east of Nagu Sandö.

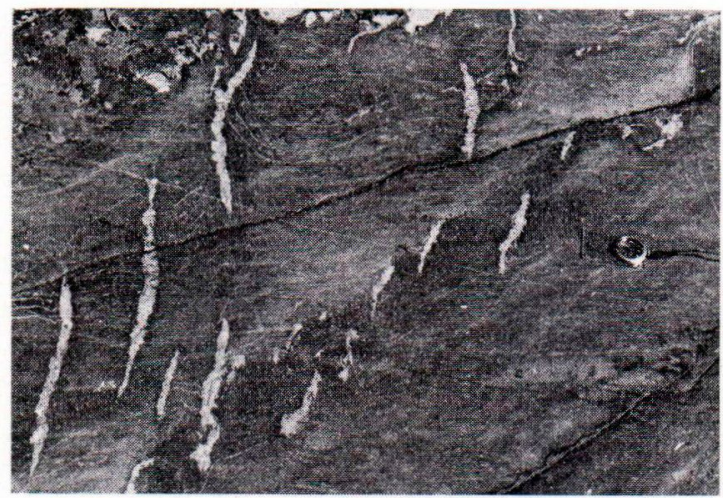

Fig. 2. Pegmatite-filled tension cracks in the axial plane. They occur here also in the light parts of the varves and some of them are surrounded by dark rims, indicating diffusion of salic minerals into the pegmatite. Islet of Haraholm, east of Nagu Sandö.

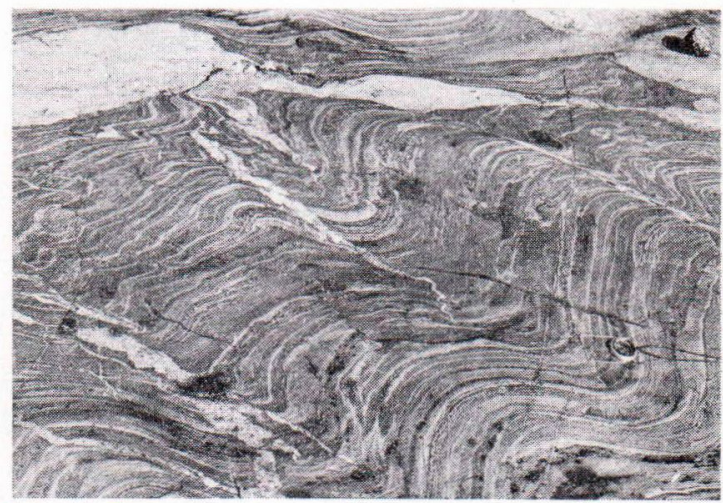

Fig. 3. Pegmatite in tension cracks in a folded finegrained gneiss. The pegmatites have been crumpled and probably also faulted by stress in the axial plane, as exhibited by the pegmatite in the middle of the photo. Western shore of Skaftö, Kumlinge.

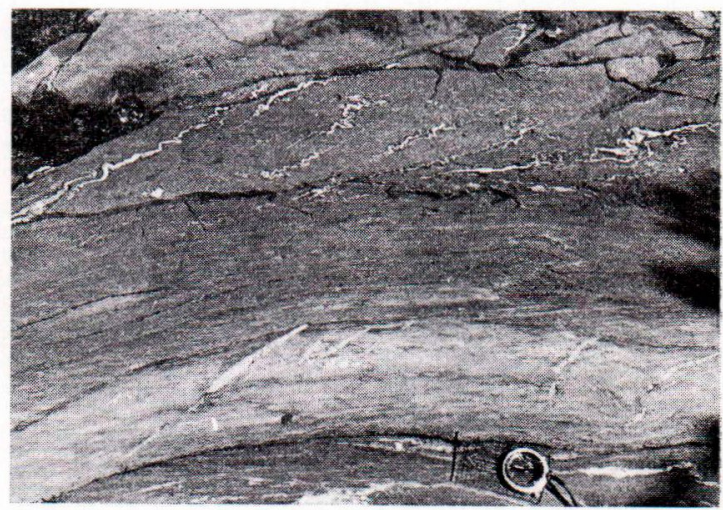

Fig. 4. Quartz-filled tension cracks in the axial plane. Country rocks are gneiss, amphibolite, and diopside amphibolite. The cracks have been conspicuously crumpled by stress in the axial plane. The undeformed quartz-lenses represent a second generation of tension cracks. Northeastern shore of Skårskär, Houtskär.

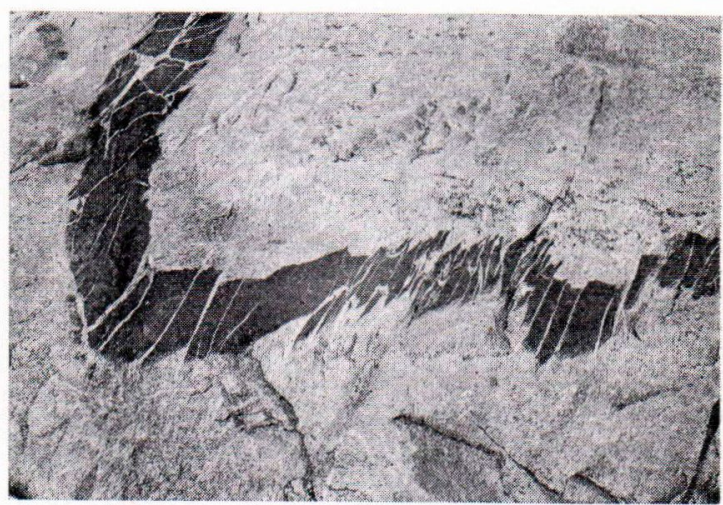

Fig. 5. Folded amphibolite layer in gneissose granite. Straight, thin tension cracks in the amphibolite parallel with axial plane have been filled with palingenic granitic material. Western shore of Karlbylandet, Kökar. 
Fig. 3 shows pegmatite lenses several metres long in a folded gneiss on Skaftö, in the commune of Kumlinge. The pegmatites lie parallel with the axial plane, and they have formed preferably in or close to the most sharply bent parts of the folded sequence. The pegmatite lens in the middle of the photo is itself folded at its western end, and in the central part it is semiplastically displaced along shear planes.

Strongly folded or crumpled quartz-filled tension fissures occur in gneisses and amphibolites on the island of Skårskär, in the commune of Houtskär (Fig. 4). They strike obliquely to the banding but lie parallel with the axial plane. Also unfolded tension fissures occur in the same exposure, preferably in the light gneisses. The crumpling indicates a remarkable shortening in the direction of the axial plane. The straight tension cracks seem to have formed later than the folded ones and could therefore be classified as a second generation.

A gneissose granite on the western shore of the island of Karlbylandet, in the commune of Kökar, contains folded and broken amphibolite layers (Fig. 5). The foliation of the granite is parallel with the axial plane of the folds in the amphibolites. These rocks are here interpreted as a highly metamorphosed formation of sedimentary rocks with intercalated volcanic layers. The folding was, at least in its latest stages, of the shear folding type. Later the shear surfaces, which are parallel with the axial plane, opened to tension fissures and became filled with salic material mobilized from the gneissose granite.

\section{Discussion}

Tension fissures have received but little attention in the literature, probably because they are considered unimportant in explaining large structures. Price has touched upon similar fissures. In one of his drawings (Price 1966, Fig. $45 \mathrm{~b}, \mathrm{p} .117)$, tension gashes appear to lie almost parallel with the axial plane; but he explains this phenomenon summarily as »failure following plastic deformation» (p. 11) and as due to »tensile residual stresses from the bending of the layers» (p. 115). One would expect tension gashes caused by residual stresses from the bending to be radially oriented and not parallel with the axial plane. Ramberg and Ghosh (1968, Figs 1 and 2) have described tension veins from Norway and pointed out that the veins parallel with the schistosity are straight in contrast to the folded veins at high angles to the schistosity. These researchers (1968, Fig. 11) also discuss the rotation of quartz-filled lenticular tension gashes in folds, but they do not discuss the origin of either type of tension fissures. H. Ramberg (personnal communication) suggests that the tension cracks on Haraholm (Figs. 1 and 2 in this paper) could be some kind of real tension fissures which have later been compressed laterally. It is self-evident that tension fissures may originate in different ways, especially as they are of different types; but these differences may likewise be due to differences in the mechanical properties of the rocks instead of on quite different processes.

The common feature of the tension fissures here described is that they lie in the axial plane and hence perpendicularly to the maximum compressive stress during the folding. These tension fissures indicate, however, the greatest stress in the axial plane or at right angles to the folding stress. These fissures are too common to warrant explaining their origin as a result of an accidental turning of the maximum stress of nearly $90^{\circ}$. Therefore one should try to interconnect these two stresses.

When a stress $\sigma_{\mathrm{x}}$ begins to work on a banded rock parallelly with the banding, the rock is first compressed elastically and thereafter it will yield in directions perpendicular to the stress, either by folding in the c-direction or by elongation in the b-direction. These deformations go on until counter-stresses, $\sigma_{\mathrm{y}}$ and $\sigma_{\mathrm{z}}$, are built up to balance the stress $\sigma_{\mathrm{x}}$. Because of friction and elasticity of the rock, the counter-stresses do not need to be equal to $\sigma_{\mathrm{x}}$ for balancing. 


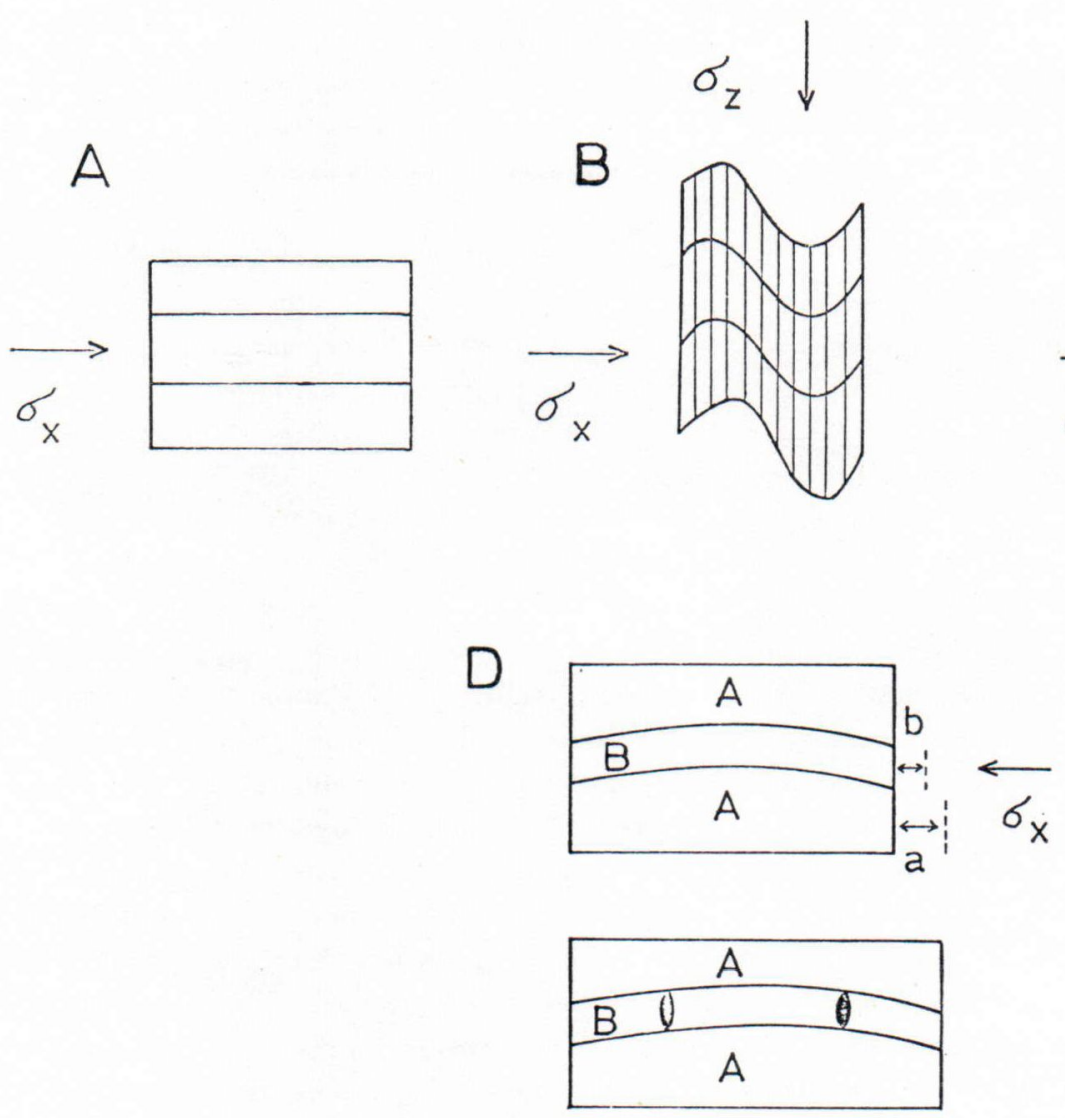

Fig. 6. Orogenic stress $\sigma_{\mathrm{x}}$ is applied on a layered rock (A) which yields elastically and thereafter with deformation and folding (B). Rock material is squeezed in $z$-direction and causes a counter-stress $\sigma_{z}$, which consists of a passive part, internal friction, and an active one, principally the elasticity and the weight of the overlying rocks. The deformation ceases when the two stresses counterbalance each other. When the orogenic stress ceases (C), $\sigma_{\mathrm{z}}$ may become the maximum stress and form tension cracks in the schistosity planes. If the rock consists of layers varying greatly in elasticity (D), small tension cracks are apt to develop in the less elastic layers when the applied stress decreases because of the differences in elastic recovery between the different layers. The elastic expansion of layer $\mathrm{A}$ is a, and of layer $\mathrm{B}$ is $\mathrm{b}$. The difference $\mathrm{a}-\mathrm{b}$ should be equal to the thickness of the tension cracks. Such cracks should form principally in the crests of the folds, where the expansion takes place along the layers.

Orogenic stresses in the crust do not work perpetually, and when the $\sigma_{\mathrm{x}}$ grows weaker, the first effect is an elastic release. If the different rock types have different elastic properties, the more elastic will lengthen perpendicularly to the axial plane more than the less elastic interlayers. Under certain circumstances, e.g., in the crest of folds, where the layers are at right angles to the axial plane, this unequal lengthening of the different layers may cause tension cracks in the less elastic layers (Figs. 1, 5 and 6 D). In these cases, tension cracks appear in certain layers and their shape depends on the absolute mechanical properties of the layers. In rather soft schists such tension cracks are irregular (Fig. 1), whereas in brittle amphibolites they are straight and of uniform breadth (Fig. 5).

When the elasticity of the rocks is released, the stresses $\sigma_{\mathrm{y}}$ and $\sigma_{\mathrm{z}}$ may still be active. These residual stresses are caused by the elastic expansive force of the surrounding crust or by the weight of the rock column above, which 
through the folding might have increased considerably. These residual stresses work in the axial plane and could cause tension fissures, especially if an axial plane schistosity has developed during the folding. In extreme cases, this compression in the axial plane might last so long, probably with interruptions, that the first tension cracks would have time to be filled with crystallized minerals so that during further compression they could be folded, while new, straight tension cracks formed (Figs. 3 and 4).
Although the tension fissures here discussed are of secondary importance to the solution of the regional structures, they represent a puzzling problem, however, and show how the crust adjusts it self to new conditions when the orogenic stresses cease.

Acknowledgements - It pleases me to thank Professor Hans Ramberg for reading the manuscript and offering his constructive criticism as well as to Mr. Paul Sjöblom, M. A., for correcting my English.

\section{REFERENCES}

Edelman, Nils (1956) Suomen geologinen kartta. Geological Map of Finland. 1: 100 000. Lehti - Sheet 1033 Nötö. Kallioperäkartan selitys. Explanation to the Map of Rocks. 44 p.

- (1960) The Gullkrona Region, SW Finland. Bull. Comm. géol. Finlande, No. 187, 87 p.

Price, Neville J. (1966) Fault and Joint Development in Brittle and Semibrittle Rock. Pergamon Press, $176 \mathrm{p}$.
Ramberg, H. and Ghosh, S. K. (1968) Deformation structures in the Hovin group schists in the Hommelvik-Hell region (Norway). Tectonophysics, Vol. 6, pp. $311-330$.

Reitan, Paul (1959) Pegmatite Veins and the Surrounding Rocks. III. Structural Control of Small Pegmatites in Amphibolite, Rytterholmen, Kragerøfjord, Norway. Norsk Geol. Tidskr., Vol. 39, pp. $175-195$.

Manuscript received, July 13, 1972. 